\title{
Percepções sociolinguísticas de estudantes
}

\section{universitários em relação ao uso do pronome tu}

\author{
Elyne Giselle de Santana Lima Aguiar Vitório* \\ UFAL
}

Recebido em: 29/06/2019

Aceito em: 02/12/2019

\begin{abstract}
Resumo: Com o intuito de analisarmos a avaliação linguística quanto ao uso do pronome tu, mensuramos o que pensam estudantes universitários do agreste alagoano sobre o seu uso. Recorremos à Teoria da Variação Linguística (LABOV, 2008 [1972]) e adotamos uma abordagem direta através da aplicação de um teste de atitude sociolinguística. A percepção dos estudantes sinaliza que não há uma avaliação negativa quanto ao uso do $t u$, mas uma associação entre a sua produção e uma maior proximidade/intimidade entre os interlocutores, revelando que tu é usado nas comunidades dos estudantes, sendo associado à variação diatópica e à relação entre os interlocutores.
\end{abstract}

Palavras-chave: Sociolinguística. Variação. Avaliação. Pronome tu.

\begin{abstract}
In order to analyze the linguistic evaluation regarding the use of the pronoun $t u$, we measure what college students from the wild of Alagoas think about its use. We used the Theory of Linguistic Variation (LABOV, 2008 [1972]) and adopted a direct approach through the application of a sociolinguistic attitude test. Students' perceptions indicate that there is no negative evaluation of the use of $t u$, but an association between their production and greater proximity/intimacy between the interlocutors, revealing that $t u$ is used in student communities, being associated with the diatopic variation and the relationship between the interlocutors.

Keywords: Sociolinguistics. Variation. Evaluation. Pronoun tu.
\end{abstract}

Resumen: Para analizar la evaluación lingüística sobre el uso del pronombre $t u$, medimos lo que piensan estudiantes universitarios sobre su uso. Recurrimos a la Teoría de la Variación Lingüística (LABOV, 2008 [1972]) y adoptamos un enfoque directo a través de la aplicación de un cuestionario de actitud sociolingüística. La percepción de los estudiantes señala que no hay una evaluación negativa en cuanto al uso del tu, sino una asociación entre su producción y una mayor proximidad/intimidad entre los interlocutores, revelando que tu se usa en comunidades estudiantiles, siendo asociado a la variación diatópica ya la relación entre los interlocutores.

Palabras clave: Sociolingüística. Variación. Evaluación. Pronombres tu. 


\section{Introdução}

A língua é um objeto social que apresenta uma heterogeneidade ordenada, o que significa considerar que ela varia e muda no tempo e no espaço e que a variação e a mudança são uma propriedade inerente ao sistema passível de sistematização. No entanto, para entender como a língua é social, é necessário descrever como as variantes linguísticas são usadas em uma comunidade, bem como mensurar como os falantes avaliam as formas em variação, tendo em vista que as variantes linguísticas além de apresentarem o mesmo significado referencial podem ainda apresentar significados sociais diferentes (LABOV, 2008 [1972]).

Entendido como o conteúdo social presente na mente do falante/ouvinte para cada situação relacionada ao comportamento linguístico (CAMPBELL-KIBLER, 2009), o significado social está relacionado aos julgamentos que os falantes fazem sobre as formas linguísticas, que podem receber valorações positivas, negativas ou neutras a depender das percepções sociolinguísticas da comunidade de fala. De acordo com Labov (2008 [1972]), essas valorações sociais influenciam o direcionamento da variação e da mudança e podem classificar as variantes linguísticas em estereótipos, marcadores ou indicadores.

Considerando que a percepção sociolinguística de uma dada variante pode ser mensurada pelas crenças e ideologias que os falantes possuem sobre a língua (CAMPBELLKIBLER, 2010), bem como as pesquisas sociolinguísticas de Silva e Vitório (2017), Vitório (2018) e Silva (2019), que mostram que, nas comunidades alagoanas analisadas, há parcas realizações de uso do $t u$, com esse pronome sendo associado a relações simétricas entre os interlocutores, analisamos, neste artigo, a percepção de estudantes da Universidade Federal de Alagoas Campus Arapiraca em relação ao uso do pronome tu na posição de sujeito.

Com o objetivo de verificar a relação entre avaliação linguística e o pronome de $2 \mathrm{PS}$, captamos a avaliação social que estudantes universitários apresentam em relação ao uso do tu. Para tanto, adotamos uma abordagem direta através de um teste de atitude linguística e consideramos sete parâmetros de julgamento, a saber, (i) percepção de uso na comunidade, (ii) crenças em relação ao próprio uso, (iii) avaliação quanto ao uso de $t u$, (iv) percepção quanto à 
variação diatópica, (v) percepção quanto à pessoa com quem se fala, (vi) percepção quanto ao nível de escolarização e (vii) percepção quanto ao preconceito linguístico. ${ }^{1}$

O artigo está estruturado da seguinte maneira: além desta seção introdutória, que apresenta as considerações iniciais da pesquisa; traçamos, na seção seguinte, um panorama dos estudos sociolinguísticos acerca da variação tu e você, focalizando como esses pronomes se comportam no estado de Alagoas; em seguida, comentamos aspectos concernentes aos pressupostos teóricos que embasam esta pesquisa e a metodologia adotada na coleta dos dados; na seção seguinte, apresentamos e discutimos os resultados obtidos; e, por fim, concluímos as discussões levantadas, ressaltando os pontos mais importantes da análise.

\section{O pronome tu em Alagoas}

Nos últimos anos no Brasil, muitas são as pesquisas sociolinguísticas tanto de base sincrônica quanto diacrônica que mostram um quadro variável na representação da segunda pessoa do singular nas variedades brasileiras (SCHERRE et al., 2015; MARTINS et al., 2015; LOPES; MARCOTULIO; OLIVEIRA, 2018). Originária do sincretismo entre as formas do paradigma tu e a forma nominal de tratamento você, advinda, via processo de gramaticalização, do tratamento Vossa Mercê, a variação tu e você é condicionada por fatores linguísticos, sociais, pragmáticos, históricos e geográficos (COUTO; LOPES, 2011).

Scherre et al. (2015), levando em consideração o percentual de uso desses pronomes e o controle da concordância entre o pronome e o verbo, propõem a existência de seis subsistemas dos pronomes de segunda pessoa no português brasileiro, conforme podemos observar na figura 1. Os autores pontuam não só que você está presente na fala dos brasileiros, sendo inclusive usado de forma mais generalizada que o $t u$, que também tem seu uso presente em grande parte do país, como também que, em regiões em que o tu não é a primeira opção da comunidade, há uma maior dificuldade de registrá-lo em entrevistas sociolinguísticas.

\footnotetext{
${ }^{1}$ O teste foi adaptado da pesquisa de Araújo e Mendonça (2018), que focaliza a avaliação dos pronomes a gente e tu entre os estudantes da Universidade Federal de Sergipe.

Revista Investigaç̃̃es, Recife, v. 32, n. 2, p. 436 - 455, Dezembro/2019
} 
Figura 1 - Mapeamento dos pronomes tu e você no português brasileiro
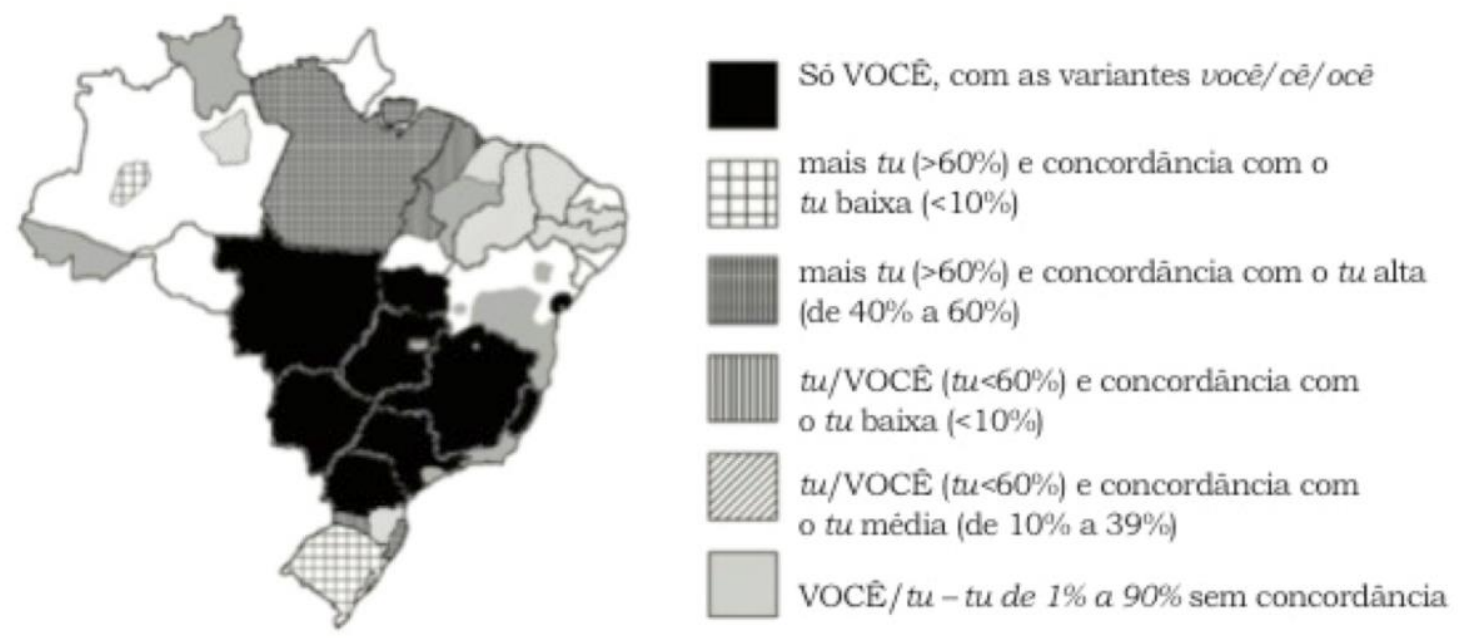

Fonte: Scherre et al. (2015, p. 142)

Silva e Vitório (2017), ao analisarem a variação você e cê na comunidade de fala do sertão alagoano, tomando por base a amostra do projeto A Língua Usada no Sertão Alagoano - Lusa, que é composta por 96 entrevistas sociolinguísticas do tipo DID (VITÓRIO, 2017), observam que só houve três realizações do pronome $t u$, como (1), (2) e (3). Segundo as autoras, as parcas realizações de $t u$ parecem indicar que esse pronome não é a primeira opção da comunidade, logo as entrevistas do tipo DID não favorecem o seu uso. O pronome você é o preferido, apresentando um percentual de 94\% (473 realizações) contra apenas 6\% (33 realizações) de cê.

(1) depois tu vai editá é? L9

(2) armaria tu é doido é? L19

(3) eu lembro que naquela ladeira ali embaixo que tu conhece né? L96

(SILVA; VITÓRIO, 2017, p. 130)

As autoras também pontuam que a variação você e cê é condicionada pelas variáveis escolaridade e paralelismo formal, com a variante cê sendo mais frequente entre os falantes do ensino médio e em contextos de paralelismo formal - cê antecedido por cê na mesma sequência discursiva. Levando em consideração esses dados, as autoras defendem o argumento de que a variação na segunda pessoa do singular no sertão alagoano se encaixa no sexto subsistema proposto por Scherre et al. (2015) - o subsistema você/tu sem concordância, no qual faz parte o uso das formas você/cê/ocê e $t u$ - com tu de $1 \%$ a 90\% sem concordância. 
Vitório (2018) analisa a variação tu e você na cidade de Maceió tomando por base os problemas de restrição e avaliação propostos pela Teoria da Variação e Mudança (LABOV, 2008 [1972]). A partir de uma amostra sincrônica composta por 72 entrevistas sociolinguísticas do tipo DID e estratificada de acordo com as variáveis sexo/gênero, escolaridade e faixa etária, a autora computa 404 realizações de tu e você, que representam 398 realizações de você - 98\% contra apenas 6 realizações de $t u-2 \%$. Esses dados mostram que, nos dados de produção, você foi o pronome preferido para representar a segunda pessoa do singular - $2 \mathrm{PS}$, o que parece indicar que tu não é a primeira forma da comunidade.

Em relação aos dados de percepção, a partir de um teste de atitudes linguísticas que abarcava nove situações hipotéticas ambientadas na cidade de Maceió e que estava dividido tomando por base as relações assimétricas ascendentes, assimétricas descendentes e simétricas, a autora apresenta percentuais de $65 \%$ para você, $16 \%$ para $t u, 5 \%$ para cê e $14 \%$ para outras formas. Esses dados revelam que, em dados de percepção, você é o pronome coringa no tratamento ao interlocutor, com o tu sendo selecionado em situações que apresentam [+ intimidade] entre os interlocutores, como a relação amigo-amigo.

Silva (2019) analisa a variação tu e você na posição de sujeito na cidade de Coité do Nóia, localizada na região do agreste alagoano, utilizando uma amostra sociolinguística do tipo D2, composta por 36 diálogos e estratificada segundo as variáveis sexo/gênero e faixa etária. A autora não só computa 520 realizações - 463 de você e 57 de $t u$, que representam percentuais de $89 \%$ de você contra $11 \%$ de $t u$, revelando que você é a forma pronominal preferida para se referir à segunda pessoa do singular, como também mostra a relevância das variáveis relação entre faixas etárias, paralelismo formal, relação entre sexos e faixa etária.

As parcas realizações de $t u$ são favorecidas nos seguintes contextos: nos diálogos entre jovem/jovem, em contexto de paralelismo - tu antecedido por tu na mesma sequência discursiva, nos diálogos entre homem/homem e entre os falantes mais jovens - 18 a 35 anos. Outro dado apresentado é o uso do tu sempre com o verbo na ${ }_{3}$ PS. Esses resultados levam a autora a argumentar que a variação tu e você na comunidade analisada se encaixa no subsistema você/tu sem concordância, no qual faz parte o uso das formas você/cê/ocê e tu - com tu de 1\% a 90\% sem concordância, conforme proposto por Scherre et al. (2015).

A partir dessas pesquisas, analisamos as percepções sociolinguísticas de estudantes universitários quanto ao uso do pronome $t u$, que, apesar de ser a forma linguística contemplada nas gramáticas normativas (BECHARA, 2008; CUNHA; CINTRA, 2008) e nos materiais didáticos que servem ao ensino de Língua Portuguesa (LOPES, 2012), tem se mostrando pouco produtiva 
nas comunidades analisadas no estado de Alagoas. Nossa hipótese é que não há uma avaliação negativa quanto ao uso desse pronome, mas uma associação entre a produção do pronome tu e uma maior proximidade/intimidade entre os interlocutores.

\section{Aporte teórico-metodológico}

Para embasar a análise dos dados, recorremos à Teoria da Variação e Mudança (LABOV, 2008 [1972]), que nasce em reação ao mito da homogeneidade linguística e propõe que a variação é uma propriedade inerente ao sistema linguístico. A língua é dotada de uma heterogeneidade ordenada. Segundo Labov (2008 [1972]), as variantes linguísticas além de apresentarem o mesmo significado referencial podem ainda apresentar significados sociais distintos, o que significa considerar que formas em variação adquirem valores sociais a depender, por exemplo, da origem geográfica do falante, do grupo social, da escolaridade.

Os significados sociais atribuídos às variantes tendem a apresentar a seguinte correlação: variantes que são utilizadas por falantes que pertencem a classes sociais mais altas tendem a receber uma valoração social positiva, sendo, na maioria das vezes, rotuladas de variantes de prestígio e chamadas de variantes cultas da língua, mesmo que não pertençam a norma padrão. Por outro lado, variantes que são utilizadas por falantes que pertencem à classe social mais baixa tendem a receber um valor social negativo e são vistas como estereótipos, ou seja, traços linguísticos socialmente marcados de forma consciente.

Mensurar como as formas linguísticas variantes são avaliadas socialmente é importante para compreender o processo de variação e os rumos da mudança linguística, tendo em vista que avaliações negativas tendem a levar ao abandono de uma dada variante linguística e impedir o processo de mudança, mas, por outro lado, avaliações positivas tendem a fazer com que uma variante seja mais usada, favorecendo o curso da mudança. Portanto, "o nível de consciência social é uma propriedade importante da mudança linguística que tem que ser determinado diretamente" (WEINREICH; LABOV; HERZOG, 2006 [1968], p. 124).

Ao analisarmos como as formas em variação são avaliadas, é possível identificar se estamos diante de traços linguísticos socialmente marcados de forma consciente, traços linguísticos social e estilisticamente estratificados ou traços linguísticos que apresentam pouca 
força avaliativa. Essa identificação revela as crenças linguísticas dos falantes, que, segundo Labov (2008 [1972]), podem ser entendidas como "um conjunto uniforme de atitudes frente à linguagem que são partilhadas por quase todos os membros da comunidade de fala, seja no uso de uma forma estigmatizada ou prestigiada da língua em questão" (LABOV, 2008 [1972], p. 208).

Para mensurarmos que significados sociais estão relacionados ao uso do pronome de $2 \mathrm{PS}$ $t u$, que é considerado uma variante padrão, mas tende a ser associado a situações comunicativas que apresentam maior informalidade e/ou intimidade entre os interlocutores (VITÓRIO, 2018; ARAUJO; MENDONÇA, 2018), adotamos uma abordagem direta de julgamento social (GARRETT; COUPLAND; WILLIAMS, 2003). Essa abordagem permite ao pesquisador perguntar diretamente aos participantes da pesquisa suas percepções, crenças, atitudes e usos sobre determinada variante linguística através de um questionário de atitudes linguísticas.

Dessa forma, para a coleta dos dados, replicamos o questionário de atitudes linguísticas de Araújo e Mendonça (2018) e levamos em consideração sete parâmetros de julgamento social, a saber, (i) percepção de uso na comunidade, (ii) crenças em relação ao próprio uso linguístico, (iii) avaliação quanto ao uso do pronome tu, (iv) percepção quanto à variação diatópica, (v) percepção quanto à pessoa com quem se fala, (vi) percepção quanto ao nível de escolarização e (vii) percepção quanto ao preconceito linguístico. O questionário é composto de sete questões subjetivas sobre o pronome $t u$ na posição sintática de sujeito. ${ }^{2}$

1. Onde você mora é comum falar tu ou você?

2. Você fala tu? Em que tipo de situação?

3. O que você acha de falar o pronome tu?

4. Você acha que o pronome tu é típico de algum lugar do Brasil? E aqui em Alagoas?

5. Você acha que o uso do tu tem a ver com a pessoa com quem se fala? Por quê?

6. Você acha que o uso do tu tem a ver com o nível de estudo da pessoa? Por quê?

7. Você acha que as pessoas que usam o pronome tu sofrem preconceito? Por quê?

A coleta de dados foi realizada na Universidade Federal de Alagoas - Campus Arapiraca durante os meses de fevereiro a abril de 2019, com 72 estudantes que nascerem, se criaram e

\footnotetext{
2 Tendo em vista que a relação entre os interlocutores em uma dada situação comunidade tem se mostrado um fator relevante para o uso do pronome tu nos estudos sociolinguísticos (COUTO; LOPES, 2011; SCHERRE et al., 2015 entre outros), incluímos em nosso questionário a questão 5 - você acha que o uso do tu tem a ver com a pessoa com quem se fala? Por quê?
}

Revista Investigações, Recife, v. 32, n. 2, p. 436 - 455, Dezembro/2019 
moram nas regiões que compõem o agreste de Alagoas. Esses estudantes pertencem à região do agreste alagoano e estudam no referido Campus. ${ }^{3}$ O Campus Arapiraca está localizado na cidade de Arapiraca, que pertence à mesorregião do agreste alagoano e fica a $130 \mathrm{Km}$ da capital do estado - Maceió, e faz parte do projeto do MEC de interiorização das IEFS. Foi inaugurado no dia 16 de setembro de 2006 e atualmente possui 24 cursos de graduação, recebendo estudantes provenientes de várias regiões do Brasil.

Após coleta dos dados, fizemos a análise qualitativa das respostas obtidas, bem como a análise quantitativa dos dados, que foi realizada com auxílio do RStudio. Procedemos dessa forma por entendermos, conforme Fernández e Díaz (2002), que o emprego de análises qualitativas e quantitativas em uma pesquisa pode ajudar a corrigir distorções associadas a cada método, uma vez que uma investigação qualitativa se caracteriza por ser subjetiva, exploratória, indutiva e não generalizável, ao passo que uma investigação quantitativa se caracteriza por ser objetiva, confirmatória, inferencial, dedutiva e generalizável.

\section{Análise e discussão dos dados}

Pesquisas sociolinguísticas sobre a variação tu e você mostram que, no estado de Alagoas, amostras sociolinguísticas do tipo DID não favorecem a realização do pronome tu (SILVA; VITÓRIO, 2017; VITÓRIO, 2018), no entanto, na pesquisa de Silva (2019), com uma amostra do tipo D2, é possível verificar um contexto variável entre tu e você na posição de sujeito. Para analisarmos a percepção de uso da variação da 2 PS na comunidade dos estudantes, perguntamos: onde você mora é comum falar tu ou você? Obtivemos, conforme gráfico 1, percentuais de 53\% para você, $11 \%$ para tu e $36 \%$ para $t u / v o c e \hat{\text {. }}$

Gráfico 1: Percepção de uso na comunidade onde mora

\footnotetext{
${ }^{3}$ Participaram da pesquisa estudantes universitários de diferentes cursos de graduação ofertados pela UFAL - Campus Arapiraca, com exceção de estudantes do curso de Letras.

Revista Investigações, Recife, v. 32, n. 2, p. 436 - 455, Dezembro/2019
} 


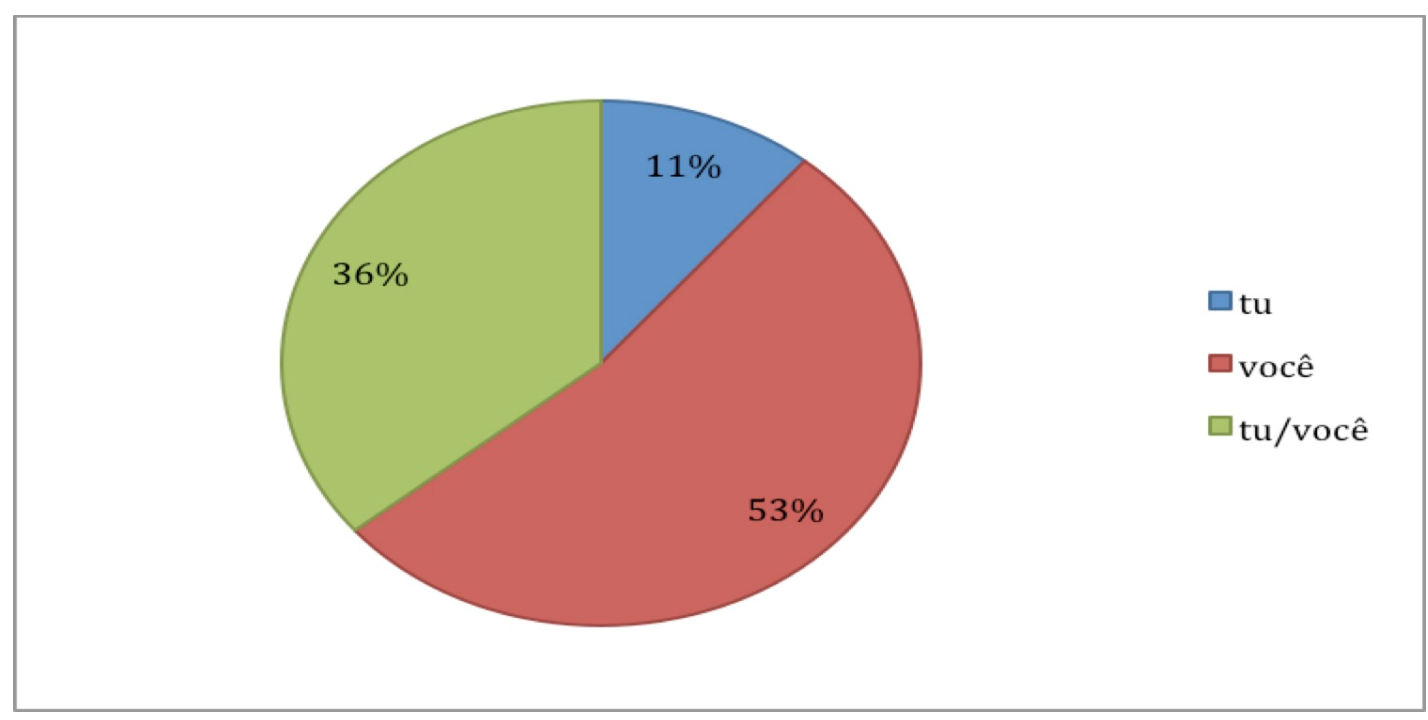

Fonte: elaborado pela autora.

Esses dados não só revelam que você é o pronome mais selecionado, corroborando os estudos sociolinguísticos de produção que mostram que, no estado de Alagoas, você é o pronome coringa para representar a $2 \mathrm{PS}$, bem como que o pronome tu também faz parte da comunidade do agreste alagoano, conforme podemos observar nos excertos (4), (5), (6) e (7). A percepção dos estudantes mostra que há a variação tu e você, mas o uso de tu é pouco frequente, ocorrendo em ambientes informais e em situações que apresentam maior intimidade entre os falantes, corroborando as discussões apresentadas por Silva (2019).

(4) onde moro ainda ouço o tu, porém é muito mais comum o você - informante 7

(5) sim, mas, na maioria das vezes, as pessoas usam mais o você - informante 40

(6) sim é comum, porém o mais usual é a substituição do tu por você, principalmente em um ambiente formal - informante 6

(7) Você sim. Tu para íntimos - informante 2

Em seguida, com o objetivo de aferirmos a percepção em relação ao próprio uso linguístico, perguntamos aos estudantes: você fala tu? Conforme gráfico 2, verificamos percentuais de $83 \%$ para sim contra apenas $17 \%$ para não. Esses dados caminham na direção contrária da percepção de uso na comunidade, bem como dos dados de produção que mostram parcas realizações de $t u$, o que nos leva a repensar o tipo de coleta de dados utilizado em comunidades onde o pronome tu não é a primeira opção para representar a 2 PS. Também podemos inferir que não há estigma quanto ao uso de tu entre os estudantes universitários.

Revista Investigaç̃̃es, Recife, v. 32, n. 2, p. 436 - 455, Dezembro/2019 
Gráfico 2: Percepção do pronome tu quanto ao próprio uso linguístico

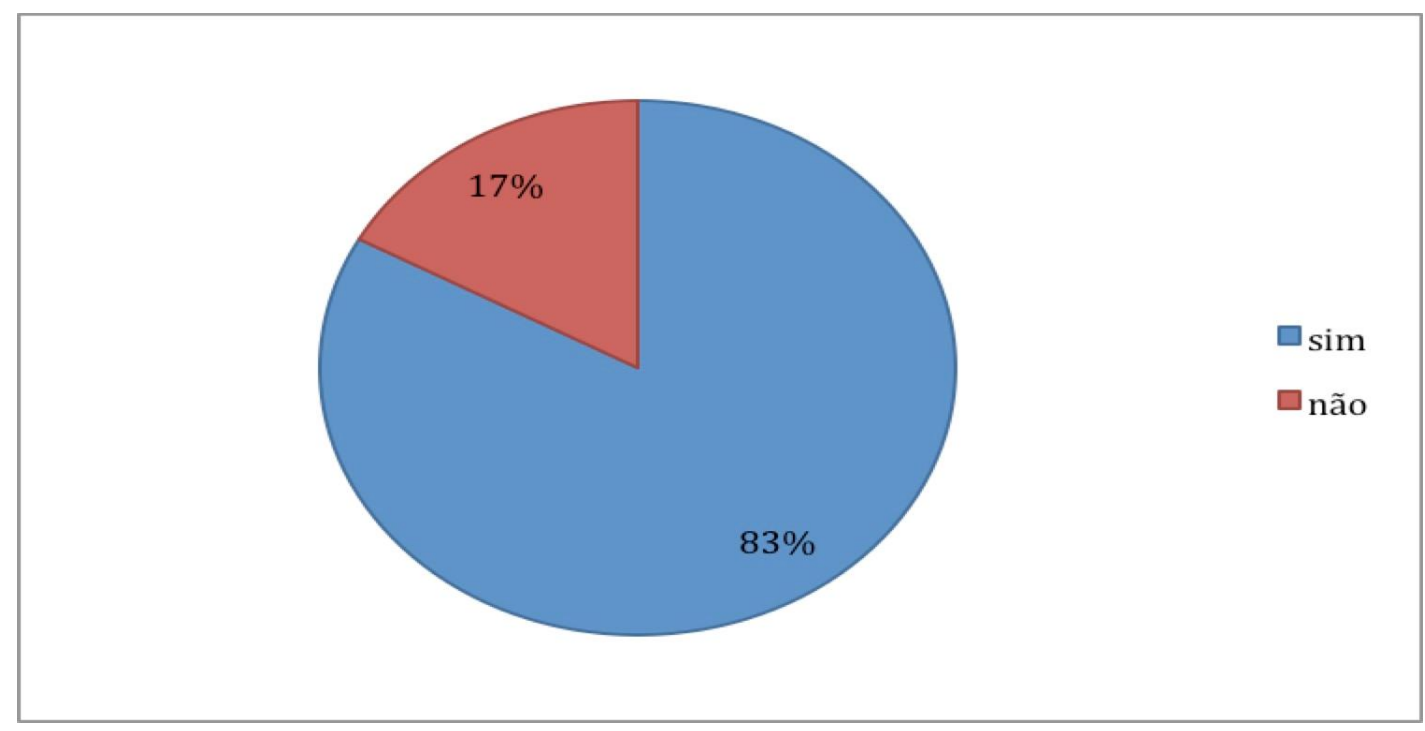

Fonte: elaborado pela autora.

Ao perguntarmos em que tipo de situação o estudante faz uso do pronome $t u$, verificamos que há uma associação entre uso do tu e situações que rementem à informalidade, como podemos observar nos excertos (8) e (9), e situações que rementem à intimidade e à familiaridade entre os falantes, como podemos observar nos excertos (10) e (11). Também observamos que o uso de tu associado a situações informais relaciona-se ao fato de não haver a concordância entre pronome sujeito e verbo, como em tu fala, tu estuda, ao invés de tu falas, tu estudas, como podemos observar nos excertos (12) e (13).

(8) de maneira informal, em conversas - informante 5

(9) só utilizo em situações informais - informante 20

(10) quando a pessoa com quem falo é próxima (amigos e parentes) - informante 64

(11) quando tenho mais intimidade com a pessoa - informante 65

(12) em situações informais, sem a conjugação correta - informante 15

(13) em ambientes mais informais porque quando uso o tu não uso com a conjugação da segunda pessoa do singular e sim da terceira - informante 42 
Em relação à questão sobre a avaliação do pronome $t u$, que objetiva aferir se há uma avaliação positiva, negativa ou neutra em relação ao uso desse pronome, perguntamos aos estudantes: o que você acha de falar o pronome tu? Observamos, conforme figura 2, que não há uma avaliação negativa, considerando o uso do pronome como "costume", "normal, "cultural", "bonito", mesmo sendo associado também a "informal", "íntimo" e "popular". O uso de tu também está relacionado a "correto", "padrão" e "formal”, o que nos remete às descrições postas nas gramáticas normativas que elegem apenas tu como pronome pessoal de $2 \mathrm{PS}$.

Figura 2: Nuvem de palavras para a avaliação de uso do pronome tu

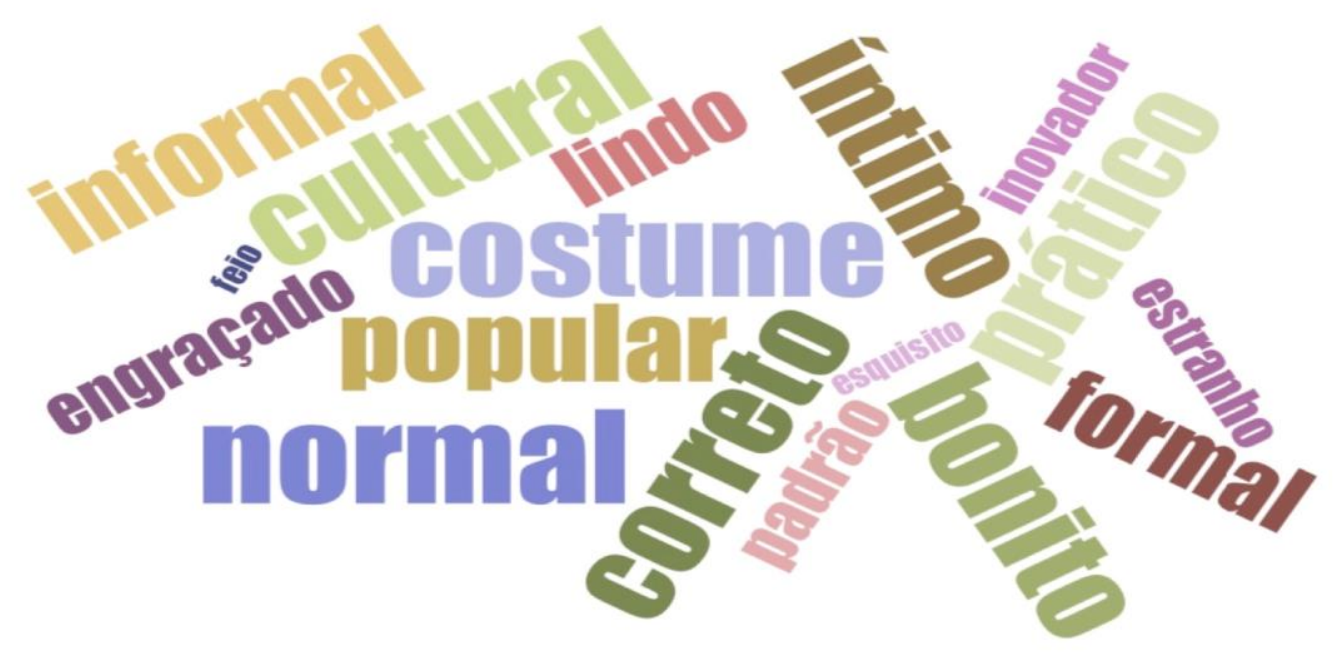

Fonte: elaborada pela autora.

Para verificarmos a percepção dos estudantes quanto à variação diatópica, perguntamos: você acha que o uso do tu é típico de algum lugar do Brasil? E aqui em Alagoas? De acordo com o gráfico 3, verificamos que $71 \%$ acreditam que sim, que o uso de tu está condicionado à variação geográfica, ao passo que $18 \%$ acreditam que não e $11 \%$ não souberam responder. Scherre et al (2015), ao mapearem a variação tu e você no Brasil, mostram a relevância da distribuição geográfica, com o tu sendo reconhecido como de uso natural em referência à $2 \mathrm{PS}$ em comunidades como Santa Catarina, Amazonas, Maranhão e Rio Grande do Sul.

Gráfico 3: Percepção do pronome tu quanto à variação diatópica 


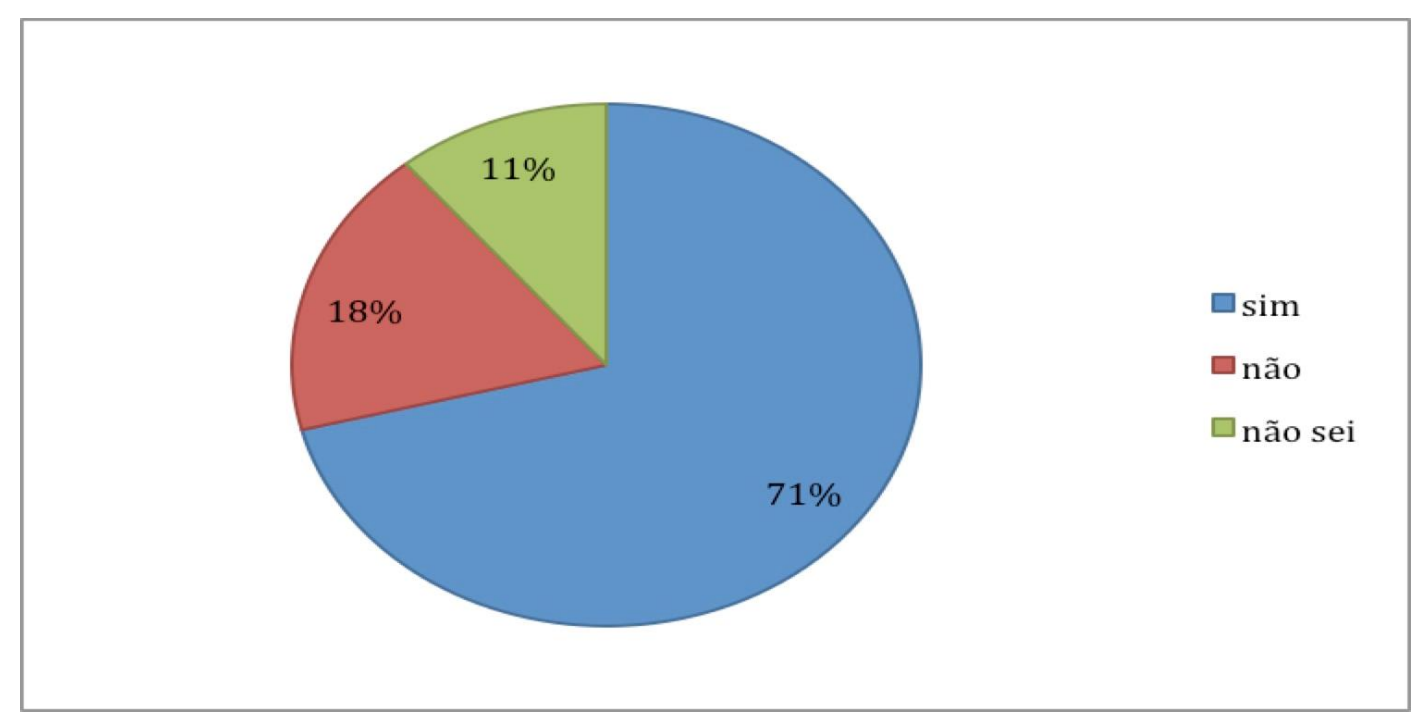

Fonte: elaborado pela autora.

Ao analisarmos a que regiões os estudantes associam ser mais frequente o uso de $t u$, verificamos, conforme figura 3, que poucas opções foram dadas nas respostas, com uma concentração nas regiões sul e nordeste. Há uma percepção de que o uso de tu é comum em Alagoas, mas pesquisas sociolinguísticas têm mostrado parcas realizações desse uso. Silva e Vitório (2017) e Vitório (2018), em amostras sociolinguísticas do tipo DID, mostram que não há uma regra variável entre tu e você nas comunidades estudadas, mas Silva (2019), ao analisar uma amostra sociolinguística do tipo D2, apresenta um percentual de $11 \%$ de $t u$.

Figura 3: Nuvem de palavras para a avaliação do pronome tu quanto à localidade

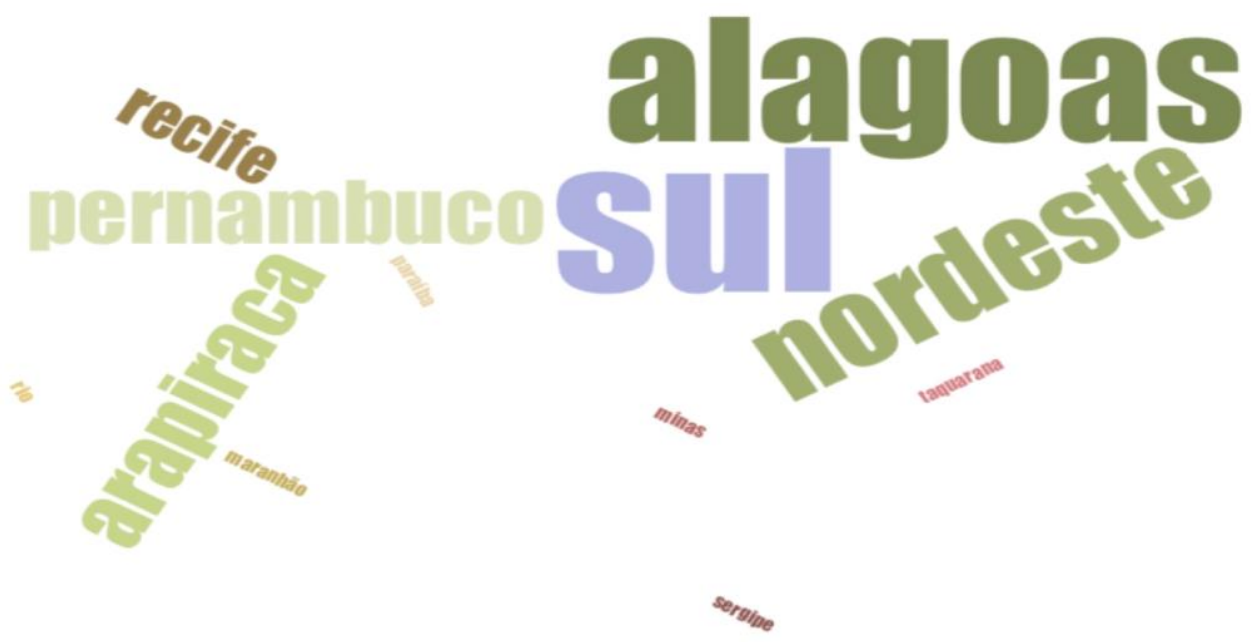

Fonte: elaborada pela autora. 
Scherre et al (2015) argumentam que o uso do pronome tu em entrevistas sociolinguísticas do tipo DID "é mais difícil de captar em áreas em que ele não parece ser a primeira forma da comunidade" (SCHERRE et al, 2015, p. 135), o que parece ser o caso das comunidades alagoanas analisadas, que tendem a selecionar o você como pronome coringa para a referência à 2 PS. No entanto, é importante registrar a presença do pronome tu nessas comunidades, um tu sem concordância expressa na forma verbal, como tu estuda, tu quer, tu vem, o que nos leva a argumentar que nos encaixamos no subsistema você/tu sem concordância.

Com o intuito de mensurarmos se a relação entre os interlocutores interfere na percepção de uso desse pronome, perguntamos aos estudantes: você acha que o uso do tu tem a ver com a pessoa com quem se fala? Por quê? De acordo com o gráfico 4, verificamos que $80 \%$ acreditam que sim, $17 \%$ acham que não e 3\% não souberam responder. Os estudantes, que acreditam que sim, afirmam que o uso de tu está relacionado à intimidade e à proximidade entre os interlocutores, como podemos observar nos excertos (14), (15) e (16), bem como a informalidade da situação comunicativa, como observamos no excerto (17).

Gráfico 4: Percepção do pronome tu quanto à relação entre os interlocutores

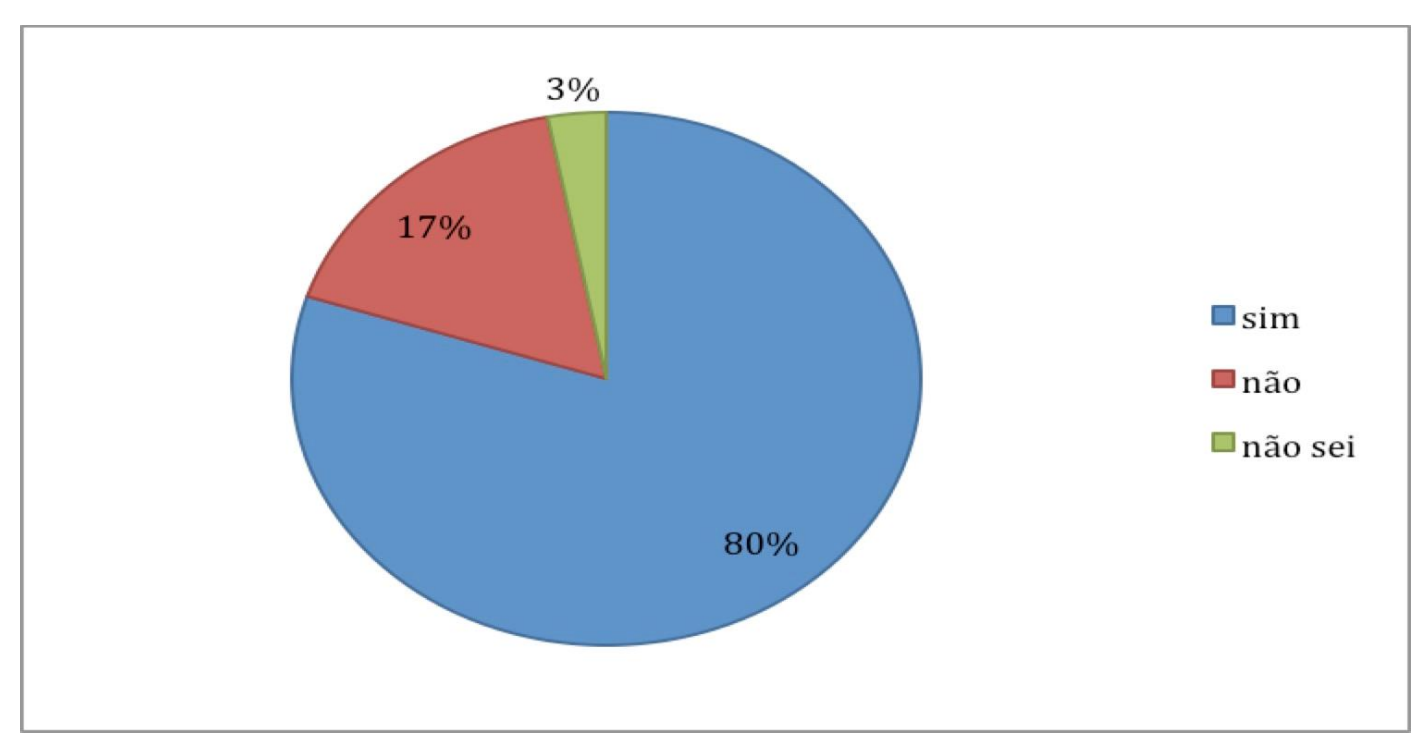

Fonte: elaborado pela autora.

(14) sim, porque usamos com pessoas íntimas - informante 27

(15) penso que sim, dependendo do grau de proximidade - informante 28

Revista Investigações, Recife, v. 32, n. 2, p. 436 - 455, Dezembro/2019 
(16) sim, me parece que tu é destinado a pessoas mais íntimas - informante 30

(17) sim, porque naturalmente o tu é acompanhando pelo verbo na $3^{\underline{a}}$ pessoa do singular, ou seja, não segue a norma padrão, sendo utilizado em momentos informais ou menos formais - informante 34

Também observamos que aqueles que responderam sim argumentam que o pronome $t u$ é de uso mais específico, referindo-se diretamente à pessoa com quem se interage, conforme observamos no excerto (18). Silva (2019) mostra que, na comunidade de Coité do Nóia, agreste alagoano, o uso do tu só ocorre em contexto específico, ao passo que você é usado tanto no contexto específico quanto no contexto genérico. Os $17 \%$ que acham que não há uma relação entre o uso do pronome tu e a pessoa com quem se fala argumentam que tal uso se relaciona à variação geográfica, como podemos observar nos excertos (19) e (20).

(18) com o tu podemos ver que é uma forma bem mais específica - informante 40

(19) acho que é atribuído de acordo com região - informante 20

(20) normalmente está ligado ao seu local de nascimento - informante 29

Em seguida, com o objetivo de aferirmos se o nível de escolarização dos falantes pode condicionar o uso do pronome $t u$, perguntamos aos estudantes: você acha que o uso do tu tem a ver com o nível de estudo da pessoa? Por quê? De acordo com o gráfico 5, observamos que $79 \%$ responderam que não, $10 \%$ que sim, $7 \%$ disseram que talvez e $4 \%$ não souberam responder, revelando que há uma percepção de que não há interferência da escola no uso desse pronome. Pesquisas sociolinguísticas tendem a apontar a importância da variável escolaridade no uso de $t u$, com os falantes menos escolarizados favorecendo mais o seu uso.

Gráfico 5: Percepção do pronome tu quanto ao nível de escolarização 


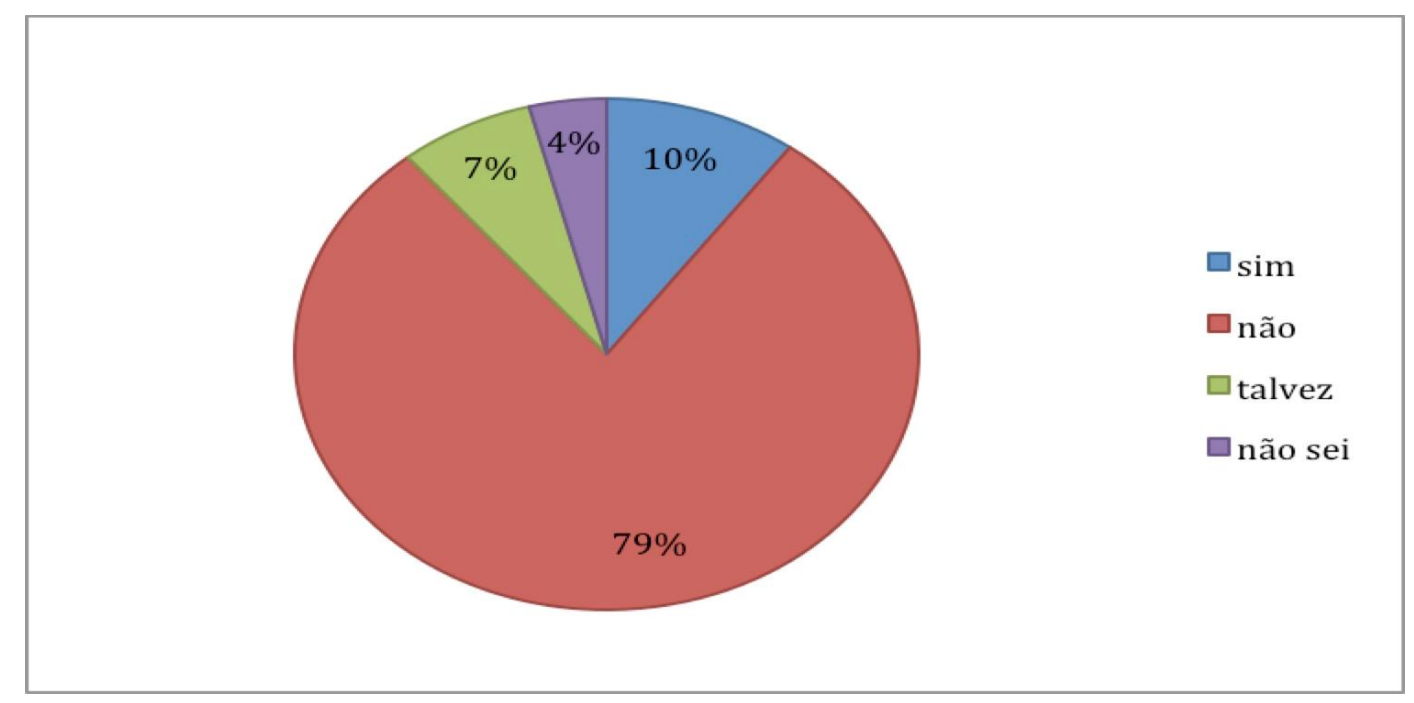

Fonte: elaborado pela autora.

Ao analisarmos as justificativas dos estudantes, verificamos que os que disseram que não há essa relação argumentam que o uso do tu está mais relacionado ao grau de intimidade entre os falantes e à variação geográfica, como podemos observar nos excertos (21) e (22), respectivamente. Há também o argumento de que não há interferência da escola porque esse uso está correto, uma vez que pronome tu faz parte da norma padrão, como observamos no excerto (23). Também há argumento de que o que está relacionado ao nível de estudo é o uso do tu mais o verbo na $2 \mathrm{PS}$, como observamos nos excertos (24) e (25).

(21) não, como já dito, está relacionado à proximidade, até mesmo pessoas bem instruídas falam normalmente o $\mathrm{tu}$ - informante 49

(22) não - acho que é da sua variação regional em que uma forma aparece mais que a outra - informante 3

(23) não, porque o uso do tu é gramaticalmente correto, podendo ser utilizado de maneira formal, mas é usado também no cotidiano, informalmente - informante 29

(24) parece que o que tem a ver com o nível de estudo é a conjugação correta, mas o uso do tu não - informante 5

(25) não, mas sua flexão nos verbos sim - informante 59

Com intuito de checarmos se há preconceito linguístico em relação ao uso do pronome tu, perguntamos aos estudantes: você acha que as pessoas que falam tu sofrem preconceito? Por $q u \hat{e}$ ? De acordo com o gráfico 6 , verificamos que $67 \%$ acreditam que não, $15 \%$ acreditam que Revista Investigações, Recife, v. 32, n. 2, p. 436 - 455, Dezembro/2019 
sim, $17 \%$ acham que depende e $1 \%$ não soube responder, revelando que há uma percepção de que não existe preconceito linguístico em relação ao uso desse pronome. Esses dados vão ao encontro dos achados apresentados por Araújo e Mendonça (2018), que mostram que 67\% acreditam que não há preconceito linguístico relacionado ao uso do tu.

Gráfico 6: Percepção do pronome tu quanto ao preconceito linguístico

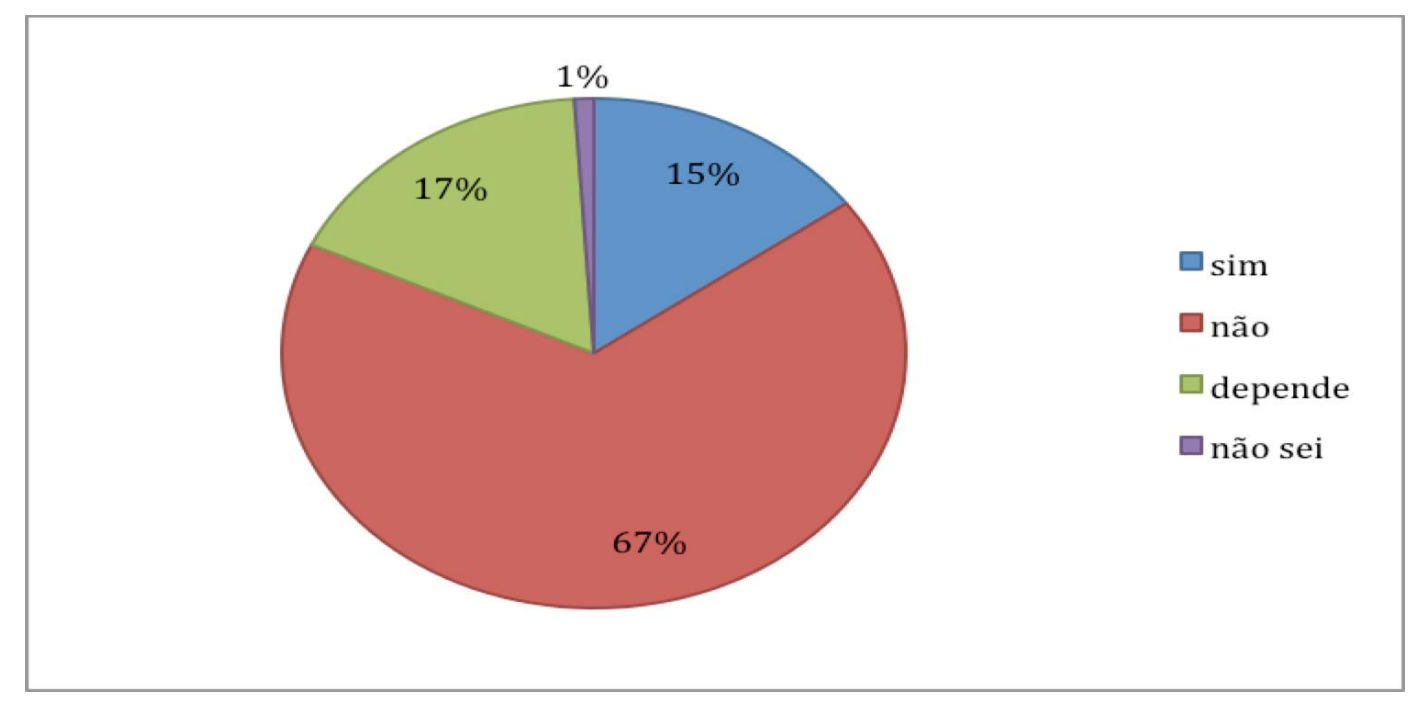

Fonte: elaborado pela autora.

Ao analisarmos as justificativas dos estudantes que acham que não há preconceito em relação ao uso do pronome $t u$, observamos, de modo geral, que tu ora é uma forma normal, comum, ora é uma forma culta, conforme os excertos (26) e (27). Os $15 \%$ que disseram sim associam ora a ausência de concordância entre pronome e verbo, como observamos nos excertos (28) e (29), ora a inadequação à situação comunicativa, como observamos no excerto (30). Os $17 \%$ que responderam depende argumentam que o preconceito está relacionado a não adequação à pessoa com quem se fala, como observamos no excerto (31).

(26) considero uma forma normal de falar - informante 14

(27) apesar de ser pouco comum o uso do tu é tipo como culto e bonito - informante 21

(28) se conjugar o verbo de forma incorreta, sim - informante 8

(29) se falam fora da norma padrão, sim - informante 7

(30) pode ser que sim dependendo do lugar e da ocasião que fale - informante 2 
(31) depende do seu interlocutor - acredito que se for fora do seu convívio, sim, pois há quem aponte o dedo como de pouco estudo quem utiliza o pronome - informante 5

Os dados mostram que, de forma geral, não há uma associação entre o pronome tu e o preconceito linguístico, mas, a depender da relação entre os interlocutores, é possível que haja preconceito, o que pode estar relacionado ao fato de $t u$ ser associado a relações simétricas, expressando familiaridade e intimidade entre os falantes. Outro ponto diz respeito à concordância verbal, que, nas variedades brasileiras, tendem a ser vistas como estigmatizadas as formas que fogem da norma padrão, logo tu com verbo na ${ }_{3} \mathrm{PS}$ contraria a norma padrão, que postula que um pronome de $2 \mathrm{PS}$ deve ser usado com verbo na $2 \mathrm{PS}$.

\section{Conclusão}

Com o objetivo de analisarmos que significados sociais estão associados ao pronome $t u$, mesuramos, a partir da abordagem direta, como estudantes universitários avaliam o uso desse pronome. Para tanto, recorremos à Teoria da Variação e Mudança (LABOV, 2008 [1972]) e consideramos os seguintes parâmetros de julgamento social: percepção de uso na comunidade, crenças em relação ao próprio uso linguístico, avaliação quanto ao uso do tu, percepção quanto à variação diatópica, percepção quanto à pessoa com quem se fala, percepção quanto ao nível de escolarização e percepção quanto ao preconceito linguístico.

A percepção dos estudantes sinaliza que o pronome $t u$ parece ser pouco produzido em sua comunidade - $11 \%$, mas muito utilizado pelos estudantes $-83 \%$, sendo associado não só à variação geográfica, caracterizando-se como de uso comum no estado de Alagoas, mas também à relação de informalidade da situação comunicativa e proximidade/intimidade entre os interlocutores. Também percebemos que não há preconceito linguístico relacionado ao uso desse pronome, que, segundo os estudantes, não é influenciado pelo nível de escolaridade dos falantes, mas pela região geográfica e pela relação entre os agentes da comunicação.

De modo geral, verificamos que não há uma avaliação negativa em relação ao uso de tu, mas uma avaliação que condiciona o seu uso à relação entre os interlocutores, ou seja, tu parece ser mais comum em relações que há um grau de intimidade maior entre os falantes, caracterizando-se como um marcador sociolinguístico. A avaliação negativa parece emergir 
quando há a associação entre o uso de tu e a concordância verbal, revelando que construções do tipo tu estuda, tu quer, tu vai, tu fez podem ser alvo de preconceito linguístico, pois contraria a norma padrão que diz que sujeito e verbo devem estar em harmonia.

\section{Referências}

ARAÚJO, A.; MENDONÇA, J. Atitudes linguísticas de universitários em relação às formas pronominais a gente e tu. Revista Tabuleiro de Letras. Vol. 12, n. 3, 2018, p. 128-144.

BECHARA, E. Moderna gramática portuguesa. Rio de Janeiro: Lucerna, 2008.

CAMPBELL-KIBLER, K. Sociolinguistics and Perception. Language and Linguistics Compass, 4/6, p. 377-389, 2010.

The nature of sociolinguistic perception. Language Variation and Change, 21, p. 135-156, 2009.

COUTO, L.; LOPES, C. (Org.). As formas de tratamento em português e em espanhol: variação, mudança e funções conversacionais. Niterói: Editora da UFF, 2011.

CUNHA, C.; CINTRA, L. Nova gramática do português contemporâneo. Rio de Janeiro: 2008.

FERNÁNDEZ, S.; DÍAZ, S. Investigación cuantitativa y cualitativa. 2002. Disponível em: $<$ http://www.fisterra.com/mbe/investiga/cuanti cuali/cuanti cualiz.pdf $>$. Acesso em: 18 jun. 2017. 
GARRETT, P.; COUPLAND, N.; WILLIAMS. A. Investigating language attitudes: social meanings of dialect, ethnicity and performance. UNIVERSITY OF WALES PRESS CARDIFF, 2003.

LABOV, W. Padrões sociolinguísticos. São Paulo: Parábola Editorial, 2008 [1972].

LOPES, C. R. S. O quadro dos pronomes pessoais: descompasso entre pesquisa e ensino. Rio de Janeiro: Matraga, v. 19, n. 30, p. 116-141, jan./jun. 2012.

LOPES, C.; MARCOTULIO, L.; OLIVEIRA, L. A atuação dos papeis sociais na mudança no sistema de tratamento no português brasileiro: análise de cartas pessoais (1870-1979). Estudos de linguística galega. Volume especial I, 2018, p. 29-44.

MARTINS, M. et al. Para um panorama sócio-diacrônico das formas de tratamento na função de sujeito na região Nordeste. LaborHistórico. Rio de Janeiro, 1(1), 2015, p. 26-48.

SCHERRE, M. et al. Variação dos pronomes "tu" e "você". In: MARTINS, M. A.; ABRAÇADO, J. (Orgs.). Mapeamento sociolinguístico do português brasileiro. São Paulo: Contexto, 2015, p. 133172.

SILVA, S. A variação pronominal de segunda pessoa do singular em Coité do Nóia /AL. 2019. Dissertação (Mestrado em Linguística e Literatura) - Universidade Federal de Alagoas. 2019.

SILVA, S.; VITÓRIO, E. A variação você e cê no sertão alagoano. Revista Leitura. V. 2, n. 59 Maceió - Jul./Dez, 2017, p. 122-142.

VITÓRIO, E. A variação tu e você em Maceió, Alagoas. Todas as Letras, São Paulo, v. 2o, n. 2, p. 85-99, maio/ago. 2018. 
A língua usada no sertão alagoano: constituição da amostra. Trabalho apresentado no III Estudos em Linguagem do Sertão. Delmiro Gouveia, jun. 2017.

WEINREICH, U.; LABOV, W.; HERZOG, M. Fundamentos empíricos para uma teoria da mudança linguística. São Paulo: Parábola Editorial, 2006 [1968].

\footnotetext{
* Doutora em Linguística e professora de Linguística da Universidade Federal de Alagoas, Campus Arapiraca.
} 